\title{
Specific use of CSII during enteral nocturnal nutrition in a child with type 1 diabetes, Hashimoto's thyroiditis, and Down syndrome
}

\author{
Uso específico de ISCI durante a nutrição enteral noturna em criança \\ com diabetes tipo 1, tireoidite de Hashimoto e síndrome de Down
}

Barbara Piccini', Sonia Toni', Lorenzo Lenzi', Federica Barni', Monica Guasti', Fina Belli², Maurizio de Martino ${ }^{3}$

\footnotetext{
1 Pediatric Diabetology Unit, Meyer Children's Hospital, University of Florence, Italy 2 Pediatric Dietology Unit, Meyer Children's Hospital, University of Florence, Italy ${ }^{3}$ Pediatric Unit, Meyer Children's Hospital, University of Florence, Italy
}

\section{SUMMARY}

The management of insulin therapy in diabetic patients who have comorbidities that involve nutritional aspects, is a major challenge for diabetes care teams. In diabetic patients with compromised nutritional status, artificial nutrition, both enteral or parenteral, may help in the treatment of chronic and acute diseases, leading to better and faster recover of the health status but, if not adequately associated with insulin therapy, it may negatively affect blood glucose levels and lead to poorer metabolic control. In particular, evidence-based recommendations for the treatment of diabetic patients during enteral nutrition therapy are not currently available and, therefore, medical practices are often based on case reports, rather than outcomes of research. We report our experience with a diabetic patient receiving nocturnal enteral feeding due to comorbidities and malnutrition, who was followed up at our centre and precociously treated with continuous subcutaneous insulin infusion after the onset of type 1 diabetes. There is great need for adequately powered randomized controlled trials to provide scientific evidence for the insulin treatment of diabetic patients undergoing enteral feeding. Ara Bras Endocrinol Metab. 2013;57(5):388-92

\section{SUMÁRIO}

Correspondence to: Sonia Toni

Pediatric Diabetology Unit, Meyer Children's Hospital, Viale Pieraccini, 24 50139 - Florence, Italy s.toni@meyer.it

Received on Dec/7/2012 Accepted on Jan/21/2013

O manejo da terapia com insulina em pacientes diabéticos que têm comorbidades que envolvam aspectos nutricionais é um grande desafio para os especialistas em diabetes. Em pacientes diabéticos com estado nutricional comprometido, a nutrição artificial, tanto enteral quanto parenteral, pode ajudar no tratamento de doenças crônicas e agudas, levando à recuperação melhor e mais rápida do estado de saúde. Entretanto, se não adequadamente associada à terapia com insulina, a nutrição artificial pode afetar negativamente os níveis de glucose e levar a um pior controle glicêmico. Particularmente, não há recomendações baseadas em evidências para o tratamento de pacientes diabéticos durante a terapia nutricional enteral e, portanto, as práticas médicas são geralmente baseadas em relatos de caso, em vez de desfechos de estudos. Relatamos nossa experiência com uma paciente diabética que recebeu nutrição enteral noturna em função de comorbidades e desnutrição, acompanhada no nosso centro e tratada precocemente com infusão subcutânea contínua de insulina depois do estabelecimento do diabetes tipo 1. Existe grande necessidade de estudos randomizados controlados para se obter evidências científicas sobre o tratamento insulínico de pacientes diabéticos que sejam submetidos à nutrição enteral. Arq Bras Endocrinol Metab. 2013;57(5):388-92

\section{INTRODUCTION}

M anaging diabetic patients with comorbidities Wresents additional difficulties, especially when nutritional aspects are involved, for example, in those patients undergoing enteral nutrition due to malabsorption or malnutrition. Strict glycemic 
control is the goal for all diabetic subjects, but in this kind of patient, this aim must be absolutely reached because additional calorie loss is not acceptable and hyperglycemia worsens clinical conditions. Replacement therapy must mimic exactly the endogenous insulin profile of non-diabetic people, and this cannot always be carried out by FMDI (flexible multiple daily injections) (1). Categories of patients commonly considered eligible for continuous subcutaneous insulin infusion (CSII) are the following: patients with elevated glycated hemoglobin (HbAlc) in MDI; with marked sameday or between-day glucose level fluctuations; with variability in insulin requirements (dawn phenomenon or particular lifestyles, such as athletes); with needle phobia; with recurrent hypoglycaemia; with very low insulin requirement (2-4). Increased diabetes care team experience, ability in pump programming and in adequate patient education, availability of insulin rapid analogues, and the modern, high precision and easy-to-use insulin pumps make CSII a possible first choice therapy in patients without classical eligibility criteria, but with particular clinical conditions, such as malnutrition or other severe illness (5-7). Enteral nutrition, unlike parenteral feeding, enables natural supply of nutrients, stimulates the immunological system, reduces overgrowth of intestinal microflora, and has a positive effect on intestinal peristalsis. Attention must be paid in diabetic patients in the selection of macronutrient intake that optimizes blood glucose and lipid control, and prevents over or underfeeding $(8,9)$. We report our experience in CSII management in a patient undergoing permanent nocturnal enteral feeding (NEF) due to comorbidities.

\section{CASE REPORT}

An 8-year-old female with Down syndrome and surgically-corrected congenital heart disease, who underwent NEF since she was 1 year old due to swallowing problems, and affected by Hashimoto's thyroiditis since the age of 2, was diagnosed with immune-mediated type 1 diabetes (T1D) in April, 2010.

Insulin replacement with MDI therapy (NPH insulin and lyspro) failed to reach adequate glycemic control: sustained hyperglycemia occurred during nocturnal enteral nutrition, despite the increased number of injections, and hypoglycemia appeared during the day because of the small amount of food eaten, and the difficulty in administering fractionated insulin doses.
The daily life of the child and her family was negatively affected because the parents had to stay awake during the night to administer insulin at least three times a night, whereas during the day the occurrence of hypoglycemia required frequent glucose administration, which the child refused strongly. During the day, the frequency of self-monitoring blood glucose (SMBG) was 6 times, including pre- and post-meal measurements, while during the night the frequency of SMBG was increased to a 2-hour interval, and rapid-acting insulin analog (RAA) was administered if glycemic levels exceeded $200 \mathrm{mg} / \mathrm{dL}$. Moreover, every insulin injection caused the patient suffering and considerable stress because of needle phobia. After a week, MDI therapy was replaced by CSII (PARADIGM VEO, Medtronic, USA) to obtain better glycemic control, reach specific glycemic targets, and allow discharge from the hospital. We chose Paradigm Veo insulin pump to perform continuous glucose monitoring (CGM), but two attempts failed, because the patient strongly refused the devices.

At the beginning of CSII, considering an insulin requirement of $0.27 \mathrm{U} / \mathrm{kg} /$ day with $\mathrm{MDI}$, a total basal rate of 3.9 units/day was programmed and administered as reported in table 1 . Enteral nutrition (500 mL of Nutrini Energy Multifibre and $300 \mathrm{~mL}$ of water) started at 9:30 pm, and continued to 6:30 am. $\mathrm{CHO}$ intake was about $10 \mathrm{~g}$ per hour. Due to the slow food intake, we administered at breakfast, lunch and dinner square wave boluses of 0.3 unit lasting 1 hour, while at snack time we administered 0.1 unit only if glycemia was over $150 \mathrm{mg} / \mathrm{dL}$.

Table 1. Basal rate at the start of CSII in an 8-year-old female with Down syndrome

\begin{tabular}{lccc}
\hline Basal rate & From & To & U/h \\
\hline 1 & Midnight & $06: 30 \mathrm{am}$ & 0.375 \\
2 & $06: 30 \mathrm{am}$ & $07: 00 \mathrm{am}$ & 0.100 \\
3 & $07: 00 \mathrm{am}$ & $09: 00 \mathrm{pm}$ & 0.025 \\
4 & $09: 00 \mathrm{pm}$ & Midnight & 0.350 \\
\hline
\end{tabular}

The theoretical insulin sensitivity factor (ISF) by the "1800 rule" was $370 \mathrm{mg} / \mathrm{dL}$ per unit, but the real ISF estimated by SMBG was $600 \mathrm{mg} / \mathrm{dL}$ per unit.

The theoretical insulin/carbohydrate ratio (ICR) by the " 500 rule" was $103 \mathrm{~g}$ of $\mathrm{CHO}$ per unit, but the real ICR, assessed by SMBG and daily food diary, was $200 \mathrm{~g}$ of $\mathrm{CHO}$ per unit, and decreased dramatically during NEF (about $27 \mathrm{~g}$ of CHO per unit).

CSII was safe and effective for the treatment of the child diabetes, leading to a significant improvement 
both in diurnal and during enteral nocturnal nutrition blood glucose levels, as demonstrated by the decreased average glycemia from $290 \mathrm{mg} / \mathrm{dL}( \pm 200 \mathrm{mg} / \mathrm{dL})$ to $150 \mathrm{mg} / \mathrm{dL}( \pm 40 \mathrm{mg} / \mathrm{dL})$.

Eight months after the onset of diabetes, when the honeymoon period ended, insulin requirement increased to a maximum of 11.8 units/day. The nocturnal insulin requirement was still elevated, even though $\mathrm{CHO}$ intake by NEF decreased. Clinical and metabolic parameters recorded during the first year of follow-up are shown in table 2.

The parents learnt to use the bolus wizard, administering a small amount of insulin (about $20 \%$ of the total dose) when the patient began the meal (pre-bolus), followed by the remaining dose at the end of the meal based on CHO counting.

Current ISF is $200 \mathrm{mg} / \mathrm{dL}$ per unit, and ICR is $30 \mathrm{~g}$ $\mathrm{CHO}$ per unit (according to the theoretical ICR) and decreases during NEF by up to $7.6 \mathrm{~g}$ of $\mathrm{CHO}$ per unit.

Neither ketoacidosis episodes nor severe hypoglycemia (defined as any hypoglycaemic event with neurologic involvement) were experienced during CSII therapy. Despite frequent acute illness, nutritional status improved (increased weight and BMI) with better compliance with oral feeding.

\section{DISCUSSION}

Diabetes mellitus is defined as a group of metabolic diseases characterized by hyperglycemia which, when untreated, can lead to long-term complications, including micro- and macrovascular complications. The Diabetes Control and Complications Trial (DCCT) demonstrated that intensive diabetes control during childhood reduces such complications significantly (10). Insulin therapy is the mainstay of treatment in children and adolescents with TID, and is a key component in the treatment of type 2 diabetes (T2D). The prevalence and incidence of T2D in the young has increased dramatically in last decades, owing to several factors such as obesity, lifestyle, and diet problems. T2D in children is most commonly managed with lifestyle modification and metformin and/or insulin, the only medications currently approved for use in children $(11,12)$.

A major aim of current insulin replacement therapy is to simulate, as closely as possible, the normal pattern of insulin secretion. This goal may be best achieved by intensified insulin treatment with basal-bolus therapy using MDI or CSII pump therapy (13). CSII is intensive insulin therapy that attempts to mimic physiologic insulin release by administration of 24-hour adjustable basal rates and flexible mealtime bolus doses. Many studies have been performed to compare CSII with MDI in terms of its efficacy and safety, with conflicting results. Metabolic control was demonstrated to be similar in some studies. On the other hand, other studies found better glycemic control with CSII (14). Reznik and cols. (15) found that CSII was effective, particularly in patients with baseline $\mathrm{HbAlc}$ of above $8 \%$, and benefits may persist in a 6-year follow-up. However, long-term follow-up studies regarding diabetes control in children with CSII are scarce.

We reported our experience with a patient undergoing nocturnal enteral feeding followed up at our centre, and treated with CSII. We witnessed improved glycemic control, improved nutritional status, and decreased glycemic excursion, both postprandial and during NEF, without hypoglycemia episodes. The increase in $\mathrm{HbAlc}$ after one year of the pump is related to the end of the honeymoon phase and to recurrent infections. During MDI replacement therapy, hyperglycemia was sustained during nocturnal enteral nutrition despite the increased number of RAA injections, and recurrent postprandial hypoglycemia appeared during the day because of the small amount of food eaten and the difficulty in administering fractionated insulin doses. We monitored blood glucose every two hours during NEF to achieve good glycemic control, since CGM failed due to the child's poor compliance. Our patient received a standard formula ( $50 \%$ carbohydrates), rather than a formula low in carbohydrates (33-40\%), but it contained larger amount of fibres, delaying gastric emptying and intestinal absorp-

Table 2. Clinical and metabolic parameters during the follow-up period in an 8-year-old female with Down syndrome during nocturnal enteral feeding (NEF)

\begin{tabular}{|c|c|c|c|c|c|c|c|}
\hline & $\begin{array}{c}\text { HbA1c } \\
\%\end{array}$ & $\begin{array}{c}\text { Weight } \\
\text { kg }\end{array}$ & BMI-SDS & $\begin{array}{c}\text { I/W ratio } \\
\mathrm{U} / \mathbf{k g}\end{array}$ & $\begin{array}{c}\text { Basal rate } \\
\text { U/24 h }\end{array}$ & $\begin{array}{c}\text { Basal/Bolus } \\
\%\end{array}$ & $\begin{array}{c}\text { NEF CHO } \\
\mathrm{gr} / \mathrm{h}\end{array}$ \\
\hline CSIl onset & 7.2 & 18 & -4.71 & 0.27 & 3.9 & $80 / 20$ & 10.3 \\
\hline 2 months after starting CSII & 6.5 & 20.4 & -3.40 & 0.16 & 2.3 & $70 / 30$ & 10.3 \\
\hline 5 months after starting CSII & 5.9 & 20 & -0.68 & 0.16 & 2.3 & $70 / 30$ & 10.3 \\
\hline 12 months after starting CSII & 7.7 & 21 & -0.20 & 0.83 & 11.8 & $67 / 33$ & 8.2 \\
\hline
\end{tabular}


tion of carbohydrates in order to achieve better glycemic control with lower insulin requirements (16).

Few studies have focused on the optimal management of hyperglycemia during enteral nutrition therapy. Clinical reviews and small uncontrolled studies recommend a variety of subcutaneous regimens, including the administration of regular insulin (every 4-6 h), NPH insulin (every 8-12 h), insulin glargine once or twice a day, or the administration of $70 / 30$ biphasic insulin 2 or 3 times daily. During critical care, continuous intravenous insulin infusion has been shown to be effective in achieving glycemic control $(17,18)$. Even though T2D is usually considered less prone to diabetic ketoacidosis (DKA) than T1D, when a precipitating cause does exist, such as acute illness or disease with severe or acute hyperglycemia or need for nutritional support, patients with T2D should receive the same insulin treatment as TID, eventually associated with oral antidiabetic drugs (OAD).

Korytkowski and cols. compared, in the first randomized controlled clinical trial on the subject, different subcutaneous insulin regimens, basal-bolus with glargine versus sliding scale regular insulin (SSRI), in non-critically ill adult inpatients with T2D receiving enteral nutrition therapy. Fifty patients with or without previous history of diabetes and with two or more blood glucose levels $>130 \mathrm{mg} / \mathrm{dL}$ were randomized to receive SSRI $(\mathrm{n}=25)$ or glargine insulin once daily ( $\mathrm{n}$ $=25)$. NPH insulin was added in the SSRI group for persistent hyperglycemia (more than two blood glucose level measurements $>180 \mathrm{mg} / \mathrm{dL}$ ). In addition, supplemental SSRI was administered every 4-6 h for any blood glucose level $>130 \mathrm{mg} / \mathrm{dL}$ in both groups. Glycemic target in both groups was glucose levels between 100 and $180 \mathrm{mg} / \mathrm{dL}$. Mean daily blood glucose, as well as daily peak value, were similar in the SSRI and glargine groups, without any significant difference both in glycemic control and in the frequency of hypoglycemia. The authors concluded that more prospective randomized studies were needed in order to investigate strategies for better glycemic control and identify specific glycemic targets in diabetic inpatients receiving nutrition support (19). Park and cols. performed a retrospective analysis on 70 patients with diabetes mellitus who required nutritional support and established that, during parenteral nutrition, an increase of insulin daily dose up to $225 \%$ from previous dose is required. The change from preadmission diabetes therapy depended on the severity of the underlying illness and on the type of feeding (greater with parenteral nutrition), but not on preadmission therapy, age of patient, or type of enteral nutrition (cyclic versus continuous) (20).

One of the most controversial issues is the distribution of the total calorie requirements and, particularly, the carbohydrate/lipid ratio in diabetic patients who might require nutritional support. The American Diabetes Association (ADA) sets out that these patients may receive either a standard formula $(50 \%$ carbohydrates $)$ or a formula low in carbohydrates (33-40\%). In contrast, the European Association for the Study of Diabetes recommends that fat content in the diet should not exceed $35 \%$, and that carbohydrate intake should be within $45-60 \%$ of the daily calorie needs. There are specific enteral formulas for diabetics containing fewer carbohydrates (35-40\%) and more fats (40-50\%), with predominance of monounsaturated fatty acids (MUFA) (> 60\% of the total fat content) (16). Currently, there are insufficient data available to address the efficacy of nutritional support, including diabetes-specific formulas, according to diabetes type (type 1 or type 2 ), especially in pediatric patients.

Besides the widely known benefits of insulin pump therapy in TID in relation to HbAlc decrease, reduced total daily insulin dose, reduced risk of hypoglycemia, and lower blood glucose variability, we want to underscore the role of the pump in the category of patients who require stricter glycemic control. CSII enables the elimination of multiple daily injections (to correct hyperglycemia and manage extra meals) and the stress related to each additional insulin administration, and is an efficacious choice to more easily reach the desired glycemic levels in malnourished patients who need nutritional support, leading to better acceptance of a new therapy in children already suffering from other severe comorbidities. If the achievement and maintenance of good metabolic control is the therapeutic goal in all diabetic patients, it is essential in those with poor nutritional status to prevent worsening of clinical conditions (21).

The tailored basal insulin rate enables the best glycemic control to be achieved, especially during NEF, mainly if tailored boluses follow exactly the patient's eating habits. We suggest starting the higher basal rate adequate to $\mathrm{NEF}$ at least 30 minutes before beginning NEF. Furthermore, to manage the unpredictability of the amount of food eaten during the meal, and to follow pancreas physiology, instead of administering the insulin dose after eating, we suggest administering a small amount of insulin (20\% of the estimated bolus) before eating (pre-bolus), and the rest of the insulin dose at the 
end of the meal. This approach enables solving problems encountered in planning the quantity of food eaten during a meal, and to give insulin in a more physiological pattern, which is much more important in patients with a poor nutritional status. Furthermore we wish underscore that the nocturnal insulin basal rate, despite the homogeneous distribution of nocturnal enteral rate, is related to age-dependent insulin requirements $(3,4)$. Our patient shows dawn-reverse phenomenon typical of prepuberty, with higher basal rate required in the first part of the night (when falling asleep) (Table 1). We point out that it is necessary to translate theoretical rules into clinical practice in particular regarding ICR and ISF, since ICR is completely different of assumed CHO during each meal compared with $\mathrm{CHO}$ introduced by enteral formulas. Furthermore, the lack of specific guidelines and the small number of patients with TID who need NEF, makes a trial-and-error approach necessary for the diabetes care team. Further research is needed to determine the role of enteral nutritional support in malnourished patients with diabetes and to establish the optimal composition of nutritional feeds to gain metabolic control, improve immune function, and achieve a satisfactory nutritional status. Randomized controlled clinical trials are needed to draw up guidelines about the use of CSII in patients who are undergoing either nocturnal or continuous enteral nutrition.

In conclusion, we recommend CSII use during enteral nocturnal nutrition because it is more flexible and the therapeutic objective may be more easily reached, if a diabetes care team with experience in pump management is involved. Moreover, CSII is more appropriate as a treatment to satisfy elevated insulin requirements due to NEF and an appropriate basal rate, instead of SSII or boluses, is the best option to control hyperglycemia caused by nocturnal enteral nutrition, enabling age-related insulin requirements during the night to be taken into account.

Disclosure: no potential conflict of interest relevant to this article was reported.

\section{REFERENCES}

1. The effect of intensive treatment of diabetes on the development and progression of long-term complications in insulin-dependent diabetes mellitus. The diabetes control and complications trial research group. N Engl J Med. 1993;329:977-86.

2. Valla V. Therapeutics of diabetes mellitus: focus on insulin analogues and insulin pumps. Exp Diabetes Res. 2010;2010:doi:10.1 1.55/2010/178372.

3. Pinelli L, Rabbone I, Salardi S, Toni S, Scaramuzza A, Bonfanti R, et al. Insulin pump therapy in children and adolescents with type 1 diabetes: the Italian viewpoint. Acta Biomed. 2008;79:57-64.
4. Danne T, Battelino T, Jarosz-Chobot P, Kordonouri O, Pánkowska E, Ludvigsson J, et al. Establishing glycaemic control with continuous subcutaneous insulin infusion in children and adolescents with type 1 diabetes: experience of the PedPump Study in 17 countries. Diabetologia. 2008;51:1594-601.

5. Phillip M, Battelino T, Rodriguez $H$, Danne T, Kaufman F; for the Consensus forum participants. Use of insulin pump therapy in the pediatric age-group. Diabetes Care. 2007;30:1653-62.

6. Clement S, Braithwaite SS, Magee MF, Ahmann A, Smith EP, Schafer RG; American Diabetes Association Diabetes in Hospitals Writing Committee. Management of diabetes and hyperglycemia in hospitals. Diabetes Care. 2004;27:553-91.

7. Cheung NW, Napier B, Zaccaria C, Fletcher JP. Hyperglycemia is associated with adverse outcomes in patients receiving total parenteral nutrition. Diabetes Care. 2005;28:2367-71.

8. Bergman M, Ravikumar S, Auerhahn C, DelSavio N, Savino J, Felig P. Insulin pump therapy improves blood glucose control during hyperalimentation. Arch Intern Med. 1984;144:2013-5.

9. Elia M, Ceriello A, Laube H, Sinclair AJ, Engfer M, Stratton RJ. Enteral nutritional support and use of diabetes-specific formulas for patients with diabetes: a systematic review. Diabetes Care. 2005;28:2267-79.

10. Effect of intensive diabetes treatment on the development and progression of long-term complications in adolescents with insulin-dependent diabetes mellitus: Diabetes Control and Complications Trial. Diabetes Control and Complications Trial Research Group. J Pediatr. 1994;125:177-88.

11. Golden SH, Sapir T. Methods for insulin delivery and glucose monitoring in diabetes: summary of comparative effectiveness review. J Manag Care Pharm. 2012;18:1-17.

12. Guidoni CM, Borges AP, Freitas Od, Pereira LR. Prescription patterns for diabetes mellitus and therapeutic implications: a population-based analysis. Arq Bras Endocrinol Metabol. 2012;56:120-7.

13. Tamborlane WV, Sikes KA. Insulin therapy in children and adolescents. Endocrinol Metab Clin North Am. 2012;41:145-60.

14. Nabhan ZM, Kreher NC, Greene DM, Eugster EA, Kronenberger W, DiMeglio LA. A randomized prospective study of insulin pump vs. insulin injection therapy in very young children with type 1 diabetes: 12-month glycemic, BMI, and neurocognitive outcomes. Pediatr Diabetes. 2009;10:202-8.

15. Reznik Y, Morera J, Rod A, Coffin C, Rousseau E, Lireux B, et al. Efficacy of continuous subcutaneous insulin infusion in type 2 diabetes mellitus: a survey on a cohort of 102 patients with prolonged follow-up. Diabetes TechnolTher. 2010;12:931-6.

16. Vaquerizo Alonso C, Grau CarmonaT, Juan Díaz M. Guidelines for specialized nutritional and metabolic support in the critically-ill patient: update. Consensus SEMICYUC-SENPE: hyperglycemia and diabetes mellitus. Nutr Hosp. 2011;26(suppl. 2):46-9.

17. Umpierrez GE. Basal versus sliding-scale regular insulin in hospitalized patients with hyperglycemia during enteral nutrition therapy. Diabetes Care. 2009;32:751-3.

18. Hsia E, Seggelke SA, Gibbs J, Rasouli N, Draznin B. Comparison of 70/30 biphasic insulin with glargine/lispro regimen in non-critically ill diabetic patients on continuous enteral nutrition therapy. Nutr Clin Pract. 2011;26:714-7.

19. Korytkowski MT, Salata RJ, Koerbel GL, Selzer F, Karslioglu E, Idriss AM, et al. Insulin therapy and glycemic control in hospitalized patients with diabetes during enteral nutrition therapy: a randomized controlled clinical trial. Diabetes Care. 2009;32:594-6.

20. Park RH, Hansell DT, Davidson LE. Management of diabetic patients requiring nutritional support. Nutrition. 1992;8:316-20.

21. Reali MF, Festini F, Neri AS, Taccetti G, Repetto T, Chiarelli F, et al. Use of continuous subcutaneous insulin infusion in cystic fibrosis patients with cystic fibrosis-related diabetes awaiting transplantation. J Cyst Fibros. 2006;5:67-8. 